\title{
The Development of Central Bank Digital Currency in China: An Analysis
}

\author{
Geoffrey Goodell \\ Centre for Blockchain Technologies \\ University College London \\ g.goodell@ucl.ac.uk
}

\author{
Hazem Danny Al Nakib \\ Centre for Blockchain Technologies \\ University College London \\ h.nakib@cs.ucl.ac.uk
}

This Version: 2021-10-26

\begin{abstract}
The People's Bank of China (PBOC) has launched an ambitious project to develop a digital currency for use in domestic, retail transactions, and is, by far, the most advanced globally in this regard. In addition to involving a diverse set of stakeholders, the PBOC established a set of fundamental principles, including privacy, inclusiveness, and conservatism, and has articulated its progress in a public document translated into English. We maintain that although both its first principles and its conclusions drawn from the research conducted by the PBOC from 2014 to date are broadly reasonable and appropriate, the PBOC has also missed some important considerations and entertained some questionable assumptions, which many central banks around the world have also done. In this analysis, we consider the strengths and weaknesses of the digital currency proposition articulated by the PBOC as it exists today, and we propose one fundamental and specific change for the PBOC and other central banks around the world: The architecture must accommodate privacy-preserving, non-custodial wallets. With this change and a related set of minor adjustments, China has an opportunity to lead the world in the implementation of a central bank digital currency (CBDC) solution that protects the authority of the central bank to implement monetary policy, preserves the role of public-sector and private-sector banking institutions, promotes the efficiency of retail transactions and businesses, satisfies regulatory objectives, and safeguards the human rights of retail consumers, including their privacy and their right to participate in the economy. We hope that the PBOC, and other central banks around the world, will have the resolve and strength of purpose to implement our proposed change and carry on with implementing a CBDC architecture that serves the interests of its users.
\end{abstract}

\section{Introduction}

In July 2021, the People's Bank of China (PBOC) published a report detailing its progress, which began in 2014, toward deploying a central bank digital currency (CBDC) in China 1, with over $\$ 5.3$ billion reported in transactions to date through various pilot programs [2]. The stated purpose of this report was to "clarify the PBOC's position" and to "explain the background, objectives and visions, design framework and policy considerations for the e-CNY system" [1. This effort to engage the general public is laudable, and, to be clear, there is much to commend in this effort, its central principles, and the general direction of its progress. In this brief response, we characterise the salient features of the proposed approach to CBDC and their applicability to the efforts underway to develop CBDC worldwide.

We observe that a potentially conflicting set of requirements, which could undermine the success of this project if left unresolved, arise from some unfounded architectural assumptions about how institutionallysupported digital currency must work. Most importantly, the PBOC proposal treats wallets as ontologically indistinguishable from accounts, a conflation made by many central banks around the world. As a result, not only does the system introduce new costs and risks related to the institutional management of such wallets, but it compels retail users to relinquish control of their assets and exposes them to the risk and harm of unwelcome profiling. This is particularly important because the general tenor of the 
discussion and debate surrounding CBDC worldwide, including by governments and central banks, has viewed $\mathrm{CBDC}$ as a general and complete substitute for physical cash.

This article is organised as follows. In the next section, we characterise the design goals and requirements identified by the PBOC. Next, we evaluate the various assumptions implicit to the approach. Then, we specify a specific set of recommendations based upon our analysis. Finally, we conclude with some remarks about the implications of this proposal for CBDC efforts currently underway within the international community.

\section{Requirements}

Arguing from first principles, the authors at the PBOC make a case for a set of desiderata for the e-CNY as a domestic retail payment system. This fact alone is significant. Some of the prevailing proposals for $\mathrm{CBDC}$ focus on addressing the inefficiencies of correspondent banking in a cross-border context 3 . This problem is certainly real and worth solving, although this perspective does not address the real danger of vanishing infrastructure to support cash, as identified by the PBOC research and experienced directly by countries such as Sweden [4. Other proposals seem to assume that CBDC would primarily support or enhance the wholesale payment infrastructure [5. However, the requirements of wholesale and retail users of cash are quite different; in particular, human consumers have human rights. Therefore, the $\mathrm{PBOC}$ is right to acknowledge that we need a purpose-built solution. The PBOC identified the following desiderata, among others, as core requirements for the design of e-CNY [1]:

- Inclusiveness. The PBOC acknowledged financial inclusion as a primary objective for CBDC, and they are right to do so. The authors specifically noted the decline of cash as a motivating factor for this objective, and they acknowledged technological progress as a contributing factor to the decline of cash. As the variable revenues associated with operating a cash infrastructure fall below the fixed costs, maintaining the cash infrastructure becomes untenable. However, although in principle anyone can acquire and possess cash, not everyone is in the position to acquire modern digital money, much less possess it. Bank deposits require banking relationships, and digital transactions require access to network connectivity, electricity, and the skills necessary to make good use of modern technology. The secular decline of cash risks jeopardising the ability for certain persons (for example, the impoverished, the elderly, and the disabled) and even entire communities (for example, the most remote) to fully participate in the modern economy. We argue that the PBOC is right to implicitly define financial inclusion in terms of ability to interact with the economy, rather than in terms of access to banking services and credit facilities, as others, including the World Bank [6], as well as several central banks and governments. CBDC might hope to provide a public option, and its many possible forms might hope to reach even the most disadvantaged groups.

At the same time, we must be cautious not to treat CBDC as a panacea for financial inclusion, as that might easily lead to considering CBDC as a direct and complete substitute for cash in circulation and to no longer include providing access to cash among the paramount policy objectives of a central bank, namely to ensure that all persons have access to the economy. The authors of the report have clearly stated that the role of the central bank includes the responsibility to ensure that the public has direct access to cash and that this responsibility would also apply in the case of CBDC. It is unclear whether the PBOC maintains this in reference to the developments in the digital age which it references, the developments in technology, or the decrease in the use of cash. In any case, it is a fundamental part of any discussion surrounding the development of a CBDC architecture that many central banks have overlooked. Public, non-discriminatory access to money ought to be an objective of every central bank globally, and the decrease in the use of cash in some locations by certain demographics does not imply that the need for cash will eventually end or that somehow, the deployment of CBDC will guarantee financial inclusion simplicitur.

- Privacy. It should come as no surprise that the PBOC expressed concern about the privacy of retail consumers. In February 2020, the Shanghai and Hong Kong Stock Exchange suspended the much-anticipated IPO of Ant Financial, following the expression of "concern about excess leverage and abuse of consumer data" by the government of China [7, an alleged practice that has surfaced in other jurisdictions, with other organisations and other governments. In effect, China acknowledged 
the dangers of allowing technology platforms to accumulate, aggregate, and analyse consumer data at scale. In particular, the risk that CBDC could become a powerful tool for predicting and influencing the behaviour of populations through surveillance is well-acknowledged [8, both by government and by private-sector intermediaries and providers of infrastructure solutions, and such an outcome is explicitly deemed undesirable by the PBOC, at least for retail transactions of "small value", for which the authors specified untraceable anonymity as a requirement 11. For these reasons, the authors of the PBOC report emphasise that the e-CNY "can be transferred without relying on a bank account" and that it supports "off-line" transactions, referring to their approach as "managed anonymity".

- Safety. The authors indicated that CBDC must be safe for retail consumers to use. The PBOC report implicitly demonstrates that safety has at least two dimensions. The first dimension involves the extent to which retail consumers should consider CBDC to be a risk-free asset, which implies that CBDC must not involve counterparty risk. CBDC, which is issued by a central bank, is risk-free by definition and constitutes a liability on the balance sheet of the central bank, as a debt owed by the central bank to the users of the CBDC, similar to banknotes and coins. However, private money, including without distinction stablecoins such as "Tether" and commercially-issued digital currency such as Facebook's renamed "Diem" (formerly "Libra" 9]), intrinsically incur counterparty risk, among a variety of other risks and costs, as the guarantors of their value could fail [10. The second dimension of safety involves the extent to which CBDC must remain available for retail consumers to access and use, must remain stable in value, and must remain widely accepted by retail merchants, particularly during periods of economic distress. This view of safety could be taken to imply that CBDC must provide a safer haven to hold one's wealth than commercial bank deposits. If so, then it could mark a significant shift away from traditional responses in periods of economic distress. Whether or not this is systemically appropriate is beyond the scope of this paper. Given the repeated use of the terms "safe" and "safety", and considering the requirements for privacy, it is fair to conclude that safety implies that retail users must be free to spend CBDC without fear that information about their private transactions could be used against them in any manner. Our understanding of the PBOC report supports the view that the PBOC agrees with this, at least for 'small value' transactions.

- Efficiency. The authors expressed concern about not only the implications of the decline of cash for financial inclusion but also the economic motivations for the decline of cash. In particular, the authors cited high costs of cash management, including "banknote design, minting and printing, transportation, deposit and withdrawal, identification, processing, reflow, destruction, [and] counterfeit protection" [1. Digital technology implicitly promises to reduce these costs, and mobile and card payments have substituted for cash in much of China and indeed much of the world. A similar degree of efficiency would be required of any public payment mechanism for that mechanism to be suitable, and competitive, in the digital economy. This relates to the speed of transacting and settlement, the user experience, and various the costs and risks involved in using a public payment mechanism in contract to private-sector solutions, payment rails, and gateways. Much of the approach to $\mathrm{CBDC}$ within the international community centres upon finding the appropriate mechanism for a public payment infrastructure to operate through private-sector participants and existing private sector solutions, and approach initially pioneered by the PBOC, and which has also been adopted in reports by the central banks of other countries, including the Bank of England, its 2020 discussion paper [11.

- Regulatory Compliance. The authors explicitly indicate that CBDC would be implemented in a manner that would be compatible with compliance requirements on money laundering and terrorist finance, which we interpret as a reference to the FATF-GAFI Recommendations [12. These recommendations stipulate that custodians must require personally identifying information for account holders. We observe that the requirement for collecting information about account holders is not necessarily incompatible with the requirement for privacy that an account holder might have; for example, today, an account holder can typically withdraw cash and spend it with minimal risk of profiling. However, as with the requirement for privacy, the requirement for compliance also has important implications for the design of the CBDC architecture.

- Interoperability. The authors identified several aspects of interoperability as requirements for CBDC. First, they noted standards compliance, citing the need to establish international standards within internationally agreed frameworks and mentioning the involvement of PBOC in efforts to 
establish standards for digital fiat currency. As of July 2021, development of standards for digital fiat currency are still in early stages. Although nascent efforts to develop international standards for digital currency are underway within standards development organisations such as ISO, CEN, ITU-T, and others, the international community and leading government organisations have yet to rally behind any particular effort. Second, the authors argued that CBDC should be compatible with established financial procedures, institutions, and regulatory processes. When combined with the requirement for efficiency, this requirement would seem to imply that it would be preferable to leverage existing procedures, e.g. for clearing, settlement, interactions with the central bank as part of the monetary base (i.e., a form of $\mathrm{M} 0$ ), and regulatory compliance, rather than to establish new procedures for CBDC. Finally, the authors argue that it will be necessary to promote a healthy ecosystem of CBDC-based services and solutions, including but not limited to wallets.

We suggest that, taken individually, every one of these requirements is reasonable and appropriate. However, some of these requirements have system-level implications for the design of CBDC, and some of these implications have been overlooked by the authors and many central banks and governments around the world. For example, under certain assumptions, the system-level implications of the requirements for inclusiveness and privacy might conflict with the system-level implications of the requirements for efficiency and regulatory compliance, in which case policymakers must undertake a balancing act in the interpretation of these priorities to achieve the optimal system architecture, with some considerations taking precedence over others. In the next section, we show that such a balancing act is not necessary. However, for a system to achieve all of the objectives, wallets must be under the possession and control of the owners of the CBDC that they contain. Otherwise, inclusiveness, safety, and privacy will be significantly curtailed, with a significant, deleterious effect on individuals, households, and society. Although some of the design features of our proposed recommendations might seem to contradict certain requirements, such as efficiency and regulatory compliance, this is actually not the case. We argue that it is possible to satisfy these requirements by reconsidering the underlying assumptions and adjusting the desired architecture to different assumptions instead. In the next section, we show how this can be achieved.

\section{Assumptions}

The authors of the PBOC report base their proposed approach on several assumptions, some of which are likely to be internally unsound. The assumptions are common among central banks and governments worldwide and require attention. In this section, we identify and characterise those assumptions. We explain why we believe that the assumptions are problematic and will raise issues that the authors and other central banks have not adequately considered. We also explain how those assumptions might interfere with the development of a design that meets the requirements outlined in the previous section and the optimal balance between efficiency, regulatory compliance, inclusiveness, and privacy.

With regard to the balancing act, we do advocate for privacy, but we do not believe that compliance implies sacrificing privacy or efficiency, safety or inclusiveness. It is fundamental understand what is meant by compliance: AML/KYC regulations and FATF-GAFI recommendations apply to asset custodians, with the purpose of preventing abuse of their privileged positions. To achieve compliance with these rules, custodians usually carry out identity checks on their account holders. We do not suggest changing such rules or procedures. Instead, we suggest that the salient characteristic of digital currency is that it can be possessed and controlled directly by its owners, outside custodial accounts. That is, without the requirement that a third party rather than the owner must possess the assets. We imagine that those who exchange cash or bank deposits for digital currency would usually be known by regulated money services businesses (authorised or licensed businesses such as banks or payments businesses).

\subsection{Wallets}

Our most significant concern arises in the use of the term "wallet". What is a wallet, exactly? The authors of the report describe a wallet as something that is provided, opened, and managed by "authorised operators" [1. These characteristics are nothing like the characteristics of physical wallets, 
and this discordance might explain the vagueness of the terminology chosen by the authors to describe their proposed wallets as "quasi-account-based" and "loosely coupled with bank accounts". In fact, the characteristics highlighted by the authors are about relationships between the owners of money and third-party gatekeepers. More specifically, they are about relationships between retail consumers and financial custodians. In other words, they are about a means (software) by which retail consumers can access their accounts, which contain assets that are ultimately under the control of a custodian. This is, of course, a significant departure from cash, which is directly possessed by its owners and is under the direct control of its owners. It therefore becomes evident that the authors' use of the term "value-based" to describe their CBDC system cannot be disaggregated from their characterisation of it as variously "account-based", "quasi-account-based", and "loosely coupled with bank accounts".

The terms "account-based", "value-based", and "quasi-account-based" were used by the PBOC. These terms are somewhat vague. We interpret "value-based" to indicate that the account holds a specific quantity of currency, as opposed to, for example, a credit score. We interpret both 'account-based' and "quasi-account-based" to mean that an asset custodian is maintaining a record that links multiple transactions to each other. We interpret 'account-based' to mean that the owner of the assets has a custodial account, which would presumably comply with AML/KYC requirements for the identification of the owner, and we interpret "quasi-account-based" as pseudonymous, akin to a pre-paid debit card. A custodial account refers to ownership and possession of the assets (in this case, the CBDC itself). For example, banks are custodians of deposits. A custodial account entails that a third party, not the owner, is in possession of the assets, and for a system to require custodial accounts implies that its users simply do not have a choice in the matter.

A close look shows that the use of the term "wallet" by the authors suggests that transactions would indeed require the involvement of an authorised gatekeeper. Therefore, what the PBOC appears to be describing is an "account-based" system wherein transactions are necessarily linked to "accounts" and not privately held software or hardware modules by the owners of those assets, as defined in ISO 22739 [13]. The main question is: To transact digital currency, must a user implicitly ask permission from an authorised business or other party that actually possesses the assets and therefore serves as gatekeeper? If so, then the system is similar to commercial bank deposits. If not, then it is similar to cash. Whilst we agree with the PBOC that it should be similar to cash, we do not agree that the approach proposed in the article actually achieves this objective.

\subsubsection{Wallets as a replacement for cash}

We understand that the use of cash is declining in industrialised countries. Part of the reason is the relative efficiency of digital payment channels. The result is that the variable revenues of operating a cash infrastructure are falling below the fixed costs, and, as a result, the maintenance of cash infrastructure is becoming increasingly untenable.

In the UK, for example, facilities to deposit and withdraw cash have become less prevalent, debit cards and e-commerce (Internet) payments via custodial accounts are capturing a larger share of payments, and brick-and-mortar merchants and vendors are increasingly refusing to accept cash. The systematic replacement of cash by intermediated forms of payment via custodial accounts is harmful to consumers. In particular, cash affords its users the following benefits that modern retail payments do not:

- Accessibility. Nearly everyone can use it. The user interface for cash is simple, it has built-in features for accessibility and security, and its users of cash (banknotes and coins) do not require special registration, contracts, bank accounts, network connectivity, or even electricity to use it to make payments.

- Non-Discrimination. Because the value of cash is intrinsic, everyone's money is as good as everyone else's. If one person gives cash to another, the amount of value that one party relinquishes is exactly equal to the amount of value that the other party gains, which is settled immediately on receipt. What cash can do is not specifically enabled or limited by the identity of its bearer, nor of any party to the transaction. 
- Privacy. Users of cash have no reason to fear that their activities will be profiled on the basis of their transactions. Most cashless payment methods leave behind a data trail that can be used to construct a detailed history of an individual's habits, location, circumstances, and psychology.

- Ownership. Cash is truly owned by its bearers. Users of cash know that their transactions will succeed without the risk that a third party might block them, in contrast to instruments that are ultimately under the control of third parties and for which their users have only limited rights.

The systematic replacement of cash by intermediated forms of payment via custodial accounts also undermines monetary sovereignty directly. Funds held as cash are the direct obligations of the central bank, whereas funds held in custodial accounts are the obligations of private-sector banks or, potentially, other potential financial services businesses that have access to central bank accounts and reserves (depending on the jurisdiction). Government deposit insurance obscures but does not eliminate the difference between these two forms of money from ordinary consumers. When consumers conduct transactions using the obligations of private-sector banks, the effectiveness of monetary policy is undermined, both because multinational banks can transparently shift the risk among currencies by taking advantage of their economies of scale and because multinational banks can reduce their reliance upon the central bank of the country in which their account holders conduct transactions, an important point that is under-researched presently and must be considered when redesigning and evaluating core economic mechanisms within society.

Additionally, stipulating that wallets must take the form of custodial relationships raises some important questions about the custodians. Governments of nations around the world, including China, have objected to the abuse of consumer data by private-sector companies. By forcing consumers to use custodial accounts to hold and transact with digital currency, consumers are exposed to these risks, mutatis mutandis. The question of how to regulate such authorised operators also introduces challenges. Establishing the governance mechanisms and oversight that will be necessary to ensure fair dealing and compliance with regulations, including not only regulations concerning customer data but also concerning unfair dealing, discrimination, and anti-competitive business practices, is no small task.

The authors of the PBOC report lightly touch on this final issue through their discussion of "managed anonymity" whereby "the PBOC sets up a firewall for e-CNY-related information, and strictly implements information security and privacy protocols, such as designating special personnel to manage information, separating e-CNY from other businesses, applying a tiered authorization system, putting in place checks and balances, and conducting internal audits" [1. Presumably, the objective of such processes would be to discourage "arbitrary" access to that information by "authorized operators", which it identifies as primarily comprising "commercial banks and licensed non-bank payment institutions" [1] that circulate the e-CNY to the public. However, as the entities that the authors call "wallets" are essentially accounts, it is not obvious that the data protection mechanisms recommended by the authors can achieve their stated goals, and, given the system-level implications highlighted, the role of system operators as arbiters of such mechanisms underscores the trade-off that is inherently being made among the guiding principles.

\subsubsection{Non-custodial wallets}

Private, non-custodial wallets would allow the bearer of digital currency to make a payment without linking the payment to any custodial account; this feature is paramount to any CBDC design. Specifically, it would be possible for a bank to identify its customer when she withdraws digital currency into her private wallet, just as it would identify her when she withdraws cash. The process of withdrawing digital currency would use privacy-enhancing technology to strip out any characteristics that could be used to link the digital currency to its owner. Then, although the digital currency held in her private wallet is not linked to her identity, the owner would not be able to spend it except by remitting it to another regulated money services business. Typically, this would be an account with the payee's bank, which would be obligated to identify the payee and associate the payee with the transaction, although the payer would remain anonymous. As with payments involving cash, there is nothing to require that the time, location, or other metadata associated with the withdrawal of CBDC from the payer's account into her private wallet would be linked with the transaction wherein CBDC is deposited into the payee's account. 
This is what we mean when we say that there is no need to compromise either privacy or compliance, or efficiency and inclusiveness, for that matter, in the design of a CBDC system: The payer is subject to regulation at the time of withdrawal, and the payee is subject to regulation at the time of the payment. At the same time, non-custodial wallets offer the following benefits:

1. The withdrawal is unlinked from the payment.

2. The payer's spending habits remain private and cannot be observed without the payer's explicit consent.

3. The payer avoids the risk of profiling.

4. The privacy is verifiable through the use of privacy-enhancing technology

5. The payer can trust mathematics rather than a trusted third party.

6. The payer is not forced to carry or use trusted hardware or vendor-specific equipment.

Moreover, this system would actually facilitate more regulatory oversight than cash, because every payment must be processed by a regulated money services businesses. We hope that central banks would consider the benefits of non-custodial wallets and endorse their implementation and deployment.

\subsection{The Use of CBDC}

The authors of the PBOC report emphasise that CBDC would be part of the monetary base (M0), not private-sector money. This is a good thing, thus ensuring that its users would hold risk-free assets. Having said that, if wallets are (by definition and per the previous section) accounts, then is this just tantamount to requiring banks to segregate the CBDC of their depositors rather than use fractional reserve banking to generate new money? This would seem bizarre, if we have understood correctly, both as a matter of policy, as well as from the standpoint of a commercial business model to generate revenue.

The authors of the PBOC report contend that because CBDC is part of the monetary base, it is a direct substitute for cash. After all, it is a direct obligation of the central bank and would allow its users to avoid intermediation by existing or incumbent payment networks. This is correct, as is their assertion that a CBDC is primarily for retail payments. At the same time, this does not answer all of the relevant questions, and we must ask how it is a substitute, for what purpose, along which dimensions, and for whom. The question of whether CBDC is a good substitute for cash and not a good substitute for anything else is less obvious. We examine both aspects of the argument, one at a time:

- Is CBDC a good substitute for cash? First of all, what are the motivating reasons and factors for people using cash for some transactions today? We can plainly identify many motivating reasons and factors, and not having a bank account is only one of them. Other factors include privacy, lack of infrastructure, the economic cost of devices, and so on. Some people live in remote villages or transact in environments in which networked or electronic payments are not an option. CBDC would not be an adequate substitute for cash in such cases, or in any of the cases where the motivating reason or factor does not apply to CBDC in the same way that it does to cash. For example, desiderata for privacy, possession, or control as justifications for using cash would not be satisfied by a system wherein a "wallet" essentially entails an "account".

- Is CBDC a good substitute for other forms of money? In the retail context, we limit our examination of this question to the other form of money most familiar to retail consumers: commercial bank deposits. If CBDC were to take the form of non-custodial tokens, then it would indeed not be a better store of value than bank deposits, as it would not be rehypothecated and would not earn interest. (Although mechanisms to simulate interest via transfer payments to bearers could be implemented [16, such mechanisms would have implications for other guiding principles identified in the PBOC report.) However, implementing CBDC as non-custodial tokens would allow owners of CBDC to make payments without involving custodial accounts, so CBDC 
might indeed substitute for bank deposits, as cash does, in a limited and specific capacity as a means of payment. Another possibility is that, from the standpoint of financial risk and notwithstanding government insurance schemes, CBDC might be safer than commercial bank deposits during periods of economic distress.

CBDC is a direct obligation of the central bank, and could rightly be seen as a form of cash that is upgraded for the digital economy. We believe that it would indeed substitute for cash in some cases, and if designed correctly, could address concerns about privacy, accessibility, ownership, and discrimination. However, even in the best circumstances, it would not be a perfect substitute across all the different motivating reasons and factors. Some of these reasons and factors are critical to citizens, particularly

the vulnerable, and involve choices and decision-making that are essential for all persons, and some of these reasons and factors are critical to the foundational purpose of every central bank to ensure that persons within their purview have efficient, ongoing, and sustainable access to the economy. We also conclude that although CBDC would not substitute for bank deposits as a store of value, it could make an excellent substitute for bank deposits as a means of payment, particularly for electronic payments in low-risk transactions that do not require the payer to be traceable.

\subsection{Privacy and Managed Anonymity}

Of course, data protection is no substitute for privacy [17. Users cannot trust what they cannot verify, and there is no way to verify that information, once revealed, has not been copied, analysed, leaked, shared, sold, stolen, or otherwise misused against the interests of the data subjects. Some central banks around the world are making a mistake by conflating data protection with privacy in the context of the design of CBDC architecture.

The authors of the PBOC report state clearly that counterparties should be anonymous for "small value" transactions, and this policy is consistent both with regulations and practices for low-risk transactions in other developed countries throughout the world and with the human right to privacy [14]. We assert that the vast majority of transactions conducted by most consumers are low-risk. Therefore, to ensure that privacy is not compromised by the de facto operating conventions of the new technology, we assume that requirements for "small value" would be specified such that the vast majority of retail transactions, and not some small subset, would fall into that category. More generally, although the term "managed anonymity" would seem to connote a prudent treatment of privacy rights, there are important caveats that could limit the effectiveness of what the authors propose, depending upon how it is implemented.

First, privacy is a public good [15], and the choice to not reveal metadata is not really a choice that individual users can make for themselves. If most people are successfully incentivised to waive their rights to privacy, then no one can be private, including those persons who did not choose to waive their rights. Second, allowing users to decline to furnish personally identifying information when opening an account does not guarantee that their transactions will remain private. Consider the case of anonymous accounts or quasi-accounts, which we understand as being comparable to pre-paid debit cards. To the extent that successive transactions with the same account constitute linked attributes about a user, the user is pseudonymous and not anonymous.

We believe that the salient question is how much privacy we want ordinary persons to have, and with "managed anonymity", the answer is not much. Inasmuch as transactions use accounts, which might be described as "wallets" (in contrast to non-custodial wallets), the successive transactions that pseudonymous users make using such accounts would be linked to each other, hence the author's reference to a "loosely-coupled account linkage". So, while a consumer could in principle use an anonymous account to make a single payment, liquidating the entire account, most typical use cases would see consumers acting as price-takers, so an exact match between the price of an item and the value in an account would be unlikely. The user of an account, having completed a purchase of value less than the value of the account, would then either use the account again for a subsequent transaction or forfeit the difference between the agreed price and the value of the account. As a result, we might conclude that while malicious actors could use anonymous accounts to achieve a reasonable level of anonymity, anonymous accounts would afford much less privacy to ordinary, non-nefarious users. 
Consumers have a right to conduct low-risk transactions with merchants, vendors, and other providers of retail goods and services, without revealing personal information that can be used to associate themselves with the transaction. For the avoidance of doubt, this includes any persistent identifier associated with the consumer as well as any reference to another transaction done by the consumer. Crucially, it is possible to regulate transactions without collecting or monitoring such personal information of the consumer that can be used to associate a payer with a transaction. In particular, it is possible to collect information about the payee for compliance with tax and AML/KYC regulations, along with relevant information about the size, location, and nature of the transaction, while allowing the payer to be anonymous. As we have elaborated separately [18, this requirement could be achieved with a CBDC system that permits transactions only by regulated money services businesses and requires payees to be accountholders or other parties who have fulfilled AML/KYC checks. We imagine that even in such systems, there would be exceptions to the rule requiring recipients to be identified, although these exceptions could be implemented outside the payment mechanism itself.

We acknowledge that 'perfect' anonymity is never really possible in practice, as the size of an anonymity set is limited by the amount of cash in-flight at any moment, and, presumably, statistical analysis of the metadata associated with recent deliveries of CBDC into private wallets, such as times and locations of the transactions, and the identities of the persons whose bank accounts had been debited. However, a strong degree of anonymity is necessary for privacy. For users of digital currency to trust the system, they must have a way to verify that their activities will not be profiled. It is a human right to have the choice to engage in transactions without being profiled, and this flows from the right to privacy.

\subsection{Accessibility}

The universality of cash is made possible by the fact that it is accessible and usable by almost everyone, even without the use of the Internet. The authors suggest that e-CNY would allow offline transactions. We are sceptical of this claim. Specifically, we recognise that it is not possible to conduct a fair exchange between two actors without a trusted third party [19]. The analogue equivalent of fair exchange is possible with physical cash as the result of the fact that once physical tokens have been sent to the payee, they cannot be unilaterally re-taken by the payer, as the transaction is settled on receipt by way of exchange of possession. With digital transactions, there is not yet a way to prove to a recipient of tokens that the payer has not and will not spend them a second time ("double-spending") without indexing some third party actor or system for record-keeping and verification. One approach to bridging the gap is to employ 'trusted computing': a combination of hardware and software that serves a master other than the user of a device. However, we note that trusted computing relies upon third-party tools and for this reason cannot be implemented with complete equanimity for all parties doing the trusting, and there will remain risks and costs to each of the parties given the reliance on third-party tools.

So, how can we prevent double-spending in an offline context? If the definition of 'offline' is framed in a way that includes third-party actors, such as local observers, then it is certainly possible to achieve fair exchange. We refer to such scenarios as disconnected rather than fully offline. Disconnected transactions can take place with local third-party trust, perhaps via a local authority tasked with enforcing transaction discipline, or via a separate device or process operated by the government. It might also be possible to have fully offline transactions if money is put in escrow beforehand and then later revealed according to some rules for redemption. But we would argue that these transaction scenarios are not offline in the same way that cash is, and for this reason, we believe that digital currency, including e-CNY, would be an incomplete substitute with limited accessibility for its users. Thus, the motivating reasons and factors for the use of cash in certain contexts is not entirely transferable to those of a CBDC, making any given CBDC a partial substitute at best.

Certainly, CBDC may help with certain aspects of inclusiveness, for example with certain groups of remote areas that have great connectivity but are not 'plugged into' the digital economy. However, seeing CBDC as a complete substitute for physical cash makes it easy to justify getting rid of cash and assuming that the policy objective of ensuring everyone's access to the economy can be achieved through CBDC. It cannot. This is especially risky where the solution being considered is one that eliminates the important privacy-preserving properties of cash. 
Cash must remain, for those that are disabled, for those without access to banking facilities or money services businesses, for those who are remotely located, for those who lack good network connectivity or appropriate infrastructure, and because cash offers a private, robust option to transfer physical objects with an agreed-upon value. These considerations are particularly important where the design of a CBDC system is assumed to require the CBDC to be associated with a third party custodian or other gatekeeper (for example, a bank or payment business) before a user can make a payment, which results in exposing individuals to profiling and discrimination based on their transactions. For the avoidance of doubt, even if central banks were to follow our advice, cash should still remain because cash and CBDC are not perfect substitutes, as we also state in Section 3.2. Thus, ensuring the continued availability for cash, and the existence of a cash-like digital payment instrument is both paramount, and aligned with the policy imperatives of central banks providing unfettered access to the economy, physical and digital in the same way they have enjoyed, or better, not worse.

\subsection{Regulatory Challenges}

The report's authors argue that the privacy problem is resolved with anonymous accounts, wherein users reveal nothing. Anonymous accounts often contravene FATF-GAFI recommendations, and, as noted above, they are not really private because they implicitly link their transactions to each other. In many countries in the developed world, custodians are subject to stringent rules limiting the size of anonymous accounts that they manage on behalf of customers. Such limits are small relative to the size of transactions that can take place anonymously using cash.

Although we assume that by reference to transactions of "small value", the authors mean to suggest that anonymous accounts would include allowances made for quasi-accounts such as pre-paid debit cards in other countries. We are sceptical that this could include transactions of size comparable to the size limits for anonymous cash transactions in other developed countries. Please note that pre-paid debit cards have stringent limits in much of the developed world. In the Eurozone, pre-paid debit cards are limited to a maximum size of $€ 150$ [20].

We note that with payments made from non-custodial wallets, the regulatory burden would be handled entirely by the receiving side, with the payer providing no identifying information. But the payer must have originally received the digital currency from a regulated money services business (whether a bank, payments business, or whatever type of regulated licenced entity in that jurisdiction), and presumably, that money services business would have already carried out appropriate checks for compliance with $\mathrm{AML} / \mathrm{KYC}$ regulations. This is analogous to the user engagement lifecycle for cash. The bank knows that Alice withdrew cash, and the recipient's bank knows that Bob deposited cash, but nobody except Alice knows that she transacted with Bob.

\section{Common Misconceptions}

We suggest that at least three logical mistakes underpin the reasoning offered by the PBOC. These three misconceptions have been adopted by many central banks following the PBOC design, as well as by others that are evaluating approaches to implementing and deploying CBDC.

The first assumption is that legal process is a sufficient barrier to protect authorities (and others, such as private platform providers and attackers) from unilaterally linking individual persons to their transactions. We can appreciate how much of the dialogue on the necessity of backdoors might lead some authorities to believe that there is global agreement that it is acceptable for authorities and other powerful groups to be able to unilaterally gain access to whatever information they like, as long as they engage in a specific bit of theatre.

This view has been rightly criticised over the years in the context of cryptography 21, 22, although it persists. For example, in the European Union, the eIDAS regulation 23] implicitly suggests that formal procedures (law) for data protection by state-approved "qualified trust providers" is sufficient to protect the interests of consumers and to keep corruption at bay. But it is a dangerous fallacy to 
use controversial regulations, or maximalist interpretations of FATF-GAFI recommendations, as a straw man, or to suggest that, under such regimes, powerful actors "cannot" access the information they want when they want to do so. In fact, they can access the information, whether or not doing so is legal. For an example of how this might play out in practice, consider the increasingly common practice of "parallel construction" by law enforcement organisations: the use of unlawful methods to gather secret evidence before constructing an argument on the basis of legally-obtained evidence 24. Separately, it is also worth noting that access to transaction information associated with an account reveals the identity of its user even if the provided identity information is not known, so the distinction among the tiers is vacuous at best.

The second assumption is that it is sufficient to compare the features of the proposed wallets to the features of existing electronic payment accounts. Essentially, this is an argument that people are already being tracked when they make electronic payments all the time, which we can agree is true, so therefore the new system introduces no new harm. Unfortunately, this argument ignores the fact that today, people have the option to make payments using cash, and that part of the explicit motivation for the proposed wallet system is to provide a public payment option that would substitute for cash in at least some cases. If achieved, such an effect would be significant whether or not cash is completely eliminated. Cash is already under significant strain in China as well as many countries worldwide, wherein merchants struggle to accept cash, given its high fixed costs and the low marginal revenues associated with supporting cash infrastructure. If consumers are given yet another option that reduces cash use, then this effect would only be amplified, and governments would soon come under pressure to stop requiring merchants to accept cash. Note that in many countries, merchants are already not required to accept cash. As a result, more transactions would be subject to the gaze of unilateral surveillance.

Instead, it should be presumed that central banks and governments would provide their citizens with unfettered access to the economy, which is both physical and, now, digital as well. Thus, access to the economy ought to be ensured both in the physical realm, through cash, and in the digital realm, through digital cash. Crucially, this access must be on the same terms and in the same manner as it has always been enjoyed. Otherwise, users of money will experience a reduction of their choices and the extent of their access to the economy, exposing them to new harms, risks, and costs.

The third assumption is that wallets are really accounts that are provided or registered by an authority as a precondition for their use. This assumption implies that authorities can control who can make payments, and, by extension, that the assets contained in wallets are really owned by the authority (either government or system operators), not by the individuals who are using the assets to make payments. To assume this is to entirely overlook non-custodial wallets and systems in which users can use wallets that they trust, without being forced to choose from among a set of solutions that give authorities what they want. It is possible to rely upon protocols rather than trusted intermediaries to carry messages and make transactions; this has been the explicit purpose of the greater part of a century of communications research, whose foundations have brought us the Internet and modern e-commerce. We do not deny that governments might want to manufacture some hardware devices, for example on behalf of certain government employees or to support groups who cannot afford devices of their own, but that does not imply that all devices must be registered or must run on trusted hardware. We also do not deny that governments might want to promulgate standards for such devices and recognise certain auditors as legitimate certifiers of compliance with those standards, but that does not imply that everyone must trust those auditors in particular if they seek to interact with the system.

\section{Recommendations}

First and foremost, we should accept that a wallet is an 'application to generate, manage, or use private and public keys' that 'can be implemented as a software or hardware module' [13. We believe that wallets should generally be brought by the consumers themselves and should generally not be provided by financial institutions, asset custodians, technology platforms, or other third parties, including commercial banks and other "authorised operators". We suggest that the PBOC and central banks around the world should explicitly recognise non-custodial wallets, subject to the following six recommendations for a $\mathrm{CBDC}$ in the digital economy: 
1. A non-custodial wallet is a wallet that is under the direct control of the consumer that owns the assets that it contains. A non-custodial wallet is not an account or quasi-account; it is not provided or administered by a third party.

2. A consumer can have an arbitrary number of non-custodial wallets, and a non-custodial wallet does not forcibly contain any identifying information that can be used to link the assets it contains to the owner of the assets.

3. A consumer can withdraw digital currency from a regulated money or payment services business into a non-custodial wallet using privacy-enhancing technology, such as blind signatures or zeroknowledge proofs, to ensure that the assets contained in the non-custodial wallet are fungible and not distinguishable or recognisable by the regulated money services business or any other parties as having been associated with the transaction in which the digital currency was withdrawn.

4. The transactions of a central bank digital currency system would be performed by regulated money services businesses.

5. A central bank digital currency system should include a mechanism to ensure that its system operators do not equivocate. This mechanism could be a distributed ledger, for example, as we have proposed elsewhere [18, 25].

\section{Conclusion}

In this analysis, we have identified a set of assumptions and potential concerns with the report by the PBOC, many of which are common among central banks globally that are adopting the PBOC design, which is arguably the most advanced CBDC design in the world at present. These include the conflation of wallets with accounts and generally employing an approach of data protection rather than privacy by design in the proposed architecture for CBDC. At the same time, the approach taken by the PBOC is laudable in many ways, including the depth with which it has developed its guiding principles which, we argue, should also be adopted by other central banks. We note that those principles might be interpreted in a manner such that some principles have conflicts with others or system-level implications that require attention. We suggest that central banks around the world are looking to the PBOC for guidance from a design standpoint. We argue that a balancing act is not needed and that all the principles can be achieved, and this can only be done if we take the users of CBDC and their privacy seriously.

It may be thought, as history has time and time again demonstrated to us, that strict compliance with existing regulations must prevail, or that the most powerful actors must benefit at the expense of the general public. Not so: The core message of our analysis is that a balancing act between regulatory compliance, efficiency, privacy and inclusiveness should not take place. Instead, policymakers should identify CBDC for its most essential use, as a substitute for cash in specific instances for certain activities, whilst interpreting the principles articulated by the PBOC in a way that does not lead to contravening the rights that users have long been afforded through the use of cash. We offer our several specific recommendations in service of this end, and we hope that the PBOC, and other central banks around the world, will consider them as they seek to develop CBDC as a way to promote a well-functioning digital economy that serves the public interest.

\section{Acknowledgements}

We thank Professor Tomaso Aste for his continued support of our ongoing work and Dann Toliver for inspiring our analysis. We acknowledge the UCL Centre for Blockchain Technologies and the Systemic Risk Centre at the London School of Economics. 


\section{References}

[1] Working Group on E-CNY Research and Development of the People's Bank of China. "Progress of Research \& Development of E-CNY in China." July 2021. [online] http://www.pbc.gov.cn/en/3688110/3688172/4157443/4293696/2021071614584691871.pdf [retreived 2021-07-16]

[2] Bloomberg News. "China's Digital Yuan Trial Reaches \$5.3 Billion in Transactions." 2021-07-16. [online] https://www.bloomberg.com/news/articles/2021-07-16/china-s-digital-yuan-trial-reaches-5-3-billion-in-transactions [retrieved 2021-08-10]

[3] Team Ripple. "BIS Describes Peak Correspondent Banking [online] https://ripple.com/insights/bis-describes-peak-correspondent-banking/ [retreived 2021-07-19]

[4] J Sennero. "Swedish banks told to safeguard cash access despite rise in digital payments." Reuters, 2018-06-11. [online] https://web.archive.org/web/20190714080523/https://www.reuters.com/article/us-sweden-banks-cash-idUSKBN1J70YY [retreived 2021-07-19]

[5] G Calle and D Eidan. "Central Bank Digital Currency: an innovation in payments." R3 White Paper, April 2020. [online] https://www.r3.com/reports/central-bank-digital-currency-an-innovation-in-payments/ [retrieved 2020-05-05]

[6] The World Bank. "Financial Inclusion: Overview." 2018-10-02. [online] https://www.worldbank.org/en/topic/financialinclusion/overview [retrieved 2021-07-15]

[7] D Goldman. "China's Attempt to Avoid the American Tech Monopoly Trap." American Affairs 5(2), Summer 2021. [online] https://americanaffairsjournal.org/2021/05/chinas-attempt-to-avoid-the-american-tech-monopoly-trap/ [retrieved 2021-07-19]

[8] A Gladstein. "Financial Freedom and Privacy in the Post-Cash World." Cato Institute. Cato Journal, Spring/Summer 2021. [online] https://www.cato.org/cato-journal/spring/summer-2021/financial-freedom-privacy-post-cash-world [retrieved 2021-07-19]

[9] V Khan and G Goodell. "Libra: Is it Really About the Money?" August 2019. In Technology, Society, and Ethics, Jeremy Pitt, Ed., ISBN: 979-8517435613, July 2021.

[10] G Gorton and J Zhang. "Taming Wildcat Stablecoins." Available at SSRN, 2021-07-17. [online] https://ssrn.com/abstract=3888752 [retrieved 2021-07-19]

[11] Bank of England. "Central Bank Digital Currency: opportunities, challenges and design." Discussion paper, 2020-03-12. [online] https://www.bankofengland.co.uk/paper/2020/central-bank-digital-currency-opportunities-challenges-and-design-discussion [retrieved 2020-03-16]

[12] Financial Action Task Force (FATF). The FATF Recommendations. Updated February 2018. [online] http://www.fatf-gafi.org/media/fatf/documents/recommendations/pdfs/FATF\%20Recommendations\%202012.pdf [retrieved 2018-09-16]

[13] International Organization for Standardization (ISO). "Blockchain and distributed ledger technologies Vocabulary." ISO/22739:2020, First edition, 2020. [online] https://www.iso.org/obp/ui/\#iso:std:iso:22739:ed-1:v1:en [retrieved 2020-12-01]

[14] United Nations General Assembly. "Universal Declaration of Human Rights." 217 (III) A. Paris, 1948. [online] https://www.ohchr.org/EN/UDHR/Documents/UDHR_Translations/eng.pdf [retrieved 2021-07-19]

[15] J Fairfield and C Engel. "Privacy as a Public Good." Duke Law Journal 65(385), 2015. [online] http://scholarship.law.duke.edu/dlj/vol65/iss3/1 [retrieved 2021-07-20]

[16] G Goodell, H Al-Nakib, and P Tasca. "Digital Currency and Economic Crises: Helping States Respond." LSE Systemic Risk Centre Special Papers SP 20, September 2020, Presented at 6th Annual Peer-to-Peer Financial Systems Workshop (P2PFISY 2020), December 2020. https://systemicrisk.ac.uk/sites/default/files/2020-09/SP-20_0.pdf

[17] H Nissenbaum. "Deregulating Collection: Must Privacy Give Way to Use Regulation?" May 2017. [online] https://doi.org/10.2139/ssrn.3092282 [retrieved 2020-10-08]

[18] G Goodell, H Nakib, and P Tasca. "A Digital Currency Architecture for Privacy and Owner-Custodianship." Future Internet 2021, 13(5), 130, May 2021. https://doi.org/10.3390/fi13050130

[19] H Pagnia and F Gärtner, "On the impossibility of fair exchange without a trusted third party." Darmstadt University of Technology Department of Computer Science Technical Report TUD-BS-1999-02, 1999. [online] http://citeseerx.ist.psu.edu/viewdoc/download; jsessionid=9D84F245D05FE33F5B67E3BB4D1C9489?doi=10.1.1.44.7863\&rep=rep1\&ty [retrieved 2021-02-13] 
[20] European Parliament. "Directive (EU) 2018/843 of the European Parliament and of the Council of 30 May 2018." 2018-05-30. [online] https://eur-lex.europa.eu/legal-content/en/TXT/?uri=CELEX:32018L0843 [retrieved 2018-09-26]

[21] H. Abelson, R. Anderson, S. Bellovin, J. Benaloh, M. Blaze, W. Diffie, J. Gilmore, M. Green, S. Landau, P. Neumann, R. Rivest, J. Schiller, B. Schneier, M. Specter, and D. Weitzner. "Keys under doormats: mandating insecurity by requiring government access to all data and communications." Journal of Cybersecurity 1(1), pp. 69-79, doi:10.1093/cybsec/tyv009, 2015-11-17. [online]

https://academiccommons.columbia.edu/doi/10.7916/D82N5D59/download [retrieved 2019-03-11]

[22] J. Benaloh. "What if Responsible Encryption Back-Doors Were Possible?" Lawfare Blog, 2018-11-29. [online] https://www.lawfareblog.com/what-if-responsible-encryption-back-doors-were-possible] [retrieved 2018-12-11]

[23] The European Parliament and the Council of the European Union. "Regulation (EU) No 910/2014 of the European Parliament and of the Council of 23 July 2014 on electronic identification and trust services for electronic transactions in the internal market and repealing Directive 1999/93/EC." EUR-Lex. 2014-07-23. [online] https://eur-lex.europa.eu/legal-content/EN/TXT/?uri=uriserv:OJ.L_.2014.257.01.0073.01.ENG [retrieved 2021-10-25]

[24] S St Vincent. "Dark Side: Secret Origins of Evidence in US Criminal Cases." Human Rights Watch, 2018-01-09. [online] https://www.hrw.org/report/2018/01/09/dark-side/secret-origins-evidence-us-criminal-cases [retrieved 2021-10-25]

[25] G Goodell and T Aste. "Can Cryptocurrencies Preserve Privacy and Comply with Regulations?" Frontiers in Blockchain, May 2019. https://doi.org/10.3389/fbloc.2019.00004 